\title{
Editorial: Como elaborar um artigo científico para publicação
}

\section{Editorial: How to prepare a scientific article for publication}

\author{
Armando Dias Ramos ${ }^{1}$ \\ Universidade Autónoma de Lisboa/Portugal \\ Editor-assistente da RBDPP \\ a.dias.ramos@gmail.com \\ p publons.com/a/1417779/ \\ orcid.org/0000-0003-0711-2366
}

\begin{abstract}
Resumo: A produção científica nunca foi tão escrutinada como nos dias que correm. Na era da informática e da informação partilhada a proliferação de revistas científicas online leva a que exista um duplo controle sobre as publicações. Não poderemos descurar que a credibilidade das revistas em linha está diretamente relacionada com a qualidade e originalidade dos artigos científicos publicados. Por outro lado, existe um maior controle sobre os artigos publicados, verificando-se exaustivamente se o mesmo não apresenta plágios. A função de controlo interpares (double-blind peer review) revela-se essencial ao permitir um escrutínio e a validação dos artigos científicos que se pretendem publicar. Escrever um artigo para publicação requer conhecimentos e técnicas apropriadas, caso contrário não estaremos na presença de um artigo científico, mas de um mero artigo de opinião. Ao longo deste editorial traçamos algumas linhas que poderão conduzir os nossos leitores, eventuais futuros autores, a um aperfeiçoamento na investigação, redação e posterior publicação de um artigo científico.
\end{abstract}

1 Doutor em Direito - Ciências Jurídicas, na Universidade Autónoma de Lisboa / Professor Adjunto convidado no Instituto Politécnico de Beja / Professor Adjunto convidado no Instituto Superior de Contabilidade e Administração de Lisboa / Professor convidado na Pós-Graduação de Gestão de Fraude Organizacional no Instituto Superior de Contabilidade e Administração de Coimbra / Docente na Escola de Polícia Judiciária / Inspetor-chefe da Polícia Judiciária. 
Palavras-chave: Metodologia; Artigo Científico; Publicação; Redação de artigos científicos.

ABSTRACT: Scientific production has never been as thoroughly examined/ debated as nowadays. In the era of Computer Science and of shared information, the proliferation of scientific magazines online leads to a double control carried out on publications. We mustn't neglect that the credibility of in line magazines is directly related to the quality and originality of the published scientific articles. On the other hand, there is a wider control over an article before it is published, checking thoroughly if it shows no plagiarism. The double-blind peer review becomes essential when allowing a scrutiny and the validation of the scientific articles intended to be published. To write an essay requires knowledge and appropriate techniques, otherwise we will not be producing a scientific article but a mere opinion piece. Throughout this editorial we draw some guidelines that could lead our readers, probable authors in the future, to an improvement in their research, writing and after publication.

KEY WORDS: Methodology; Scientific Article; Publication; Writing of Scientific Articles.

A tarefa de escrever um artigo científico poderá ser árdua por exigir uma investigação cuidada e evitar redundâncias de artigos já publicados. Para minimizar o trabalho o seu autor deve debruçar-se sobre matérias nas quais se sinta à vontade ou tenha um domínio mais exaustivo. Esta técnica facilita, desde logo, o trabalho que o autor irá ter nos próximos passos até à conclusão do seu artigo. Deverá não se cair na tentação de escrever artigos para publicação apenas para construir um currículo. A demanda de um artigo científico deve ser encarada como uma função nobre, que exige muitas pesquisas, leituras e confronto de ideias entre os diversos autores, levando a que no final resulte um texto que contribua para o avanço da ciência na área em que se está a escrever.

Será, desde já, pertinente debruçarmo-nos sobre o que se deverá entender por cientificidade de um artigo. Como nos ensina Umberto Eco, "uma pesquisa é científica quando responde aos seguintes requisitos: 1) A pesquisa debruça-se sobre um objeto reconhecível e definido de tal modo que seja igualmente reconhecível pelos outros; [...] 2) A pesquisa 
deve dizer sobre esse objeto coisas que não tenham já sido ditas ou rever com uma ótica diferente coisas que já foram ditas; [...] 3) A pesquisa deve ser útil aos outros; [...] e, 4) A pesquisa deve fornecer os elementos para a confirmação e para a rejeição das hipóteses que apresenta e, portanto, deve fornecer os elementos para uma possível continuação pública"². Outros autores utilizam a expressão "método", como o conjunto de procedimentos que compõem um projeto de investigação ${ }^{3}$.

Não se deverá confundir artigo científico com uma tese ou dissertação, embora o grau de exigência deva ser o mesmo. O artigo deverá ser um relatório de uma investigação realizada, no qual se vertem os problemas ou questões iniciais, o desenvolvimento efetuado e as conclusões. Diferentemente, a tese ou dissertação abarca um estudo mais aprofundado e exige a aplicação de outros métodos de investigação ${ }^{4}$.

O labor científico de um artigo começa, desde logo, pela delimitação da escolha do tema a tratar e pela busca do estado da arte nesse quadrante ${ }^{5}$. Uma breve pesquisa, em índices bibliotecários ${ }^{6}$, permite aferir se o tema

2 Eco, Como se faz uma tese em ciências humanas, pp. 51 a 56.

3 "A definição de método é complexa e pode sugerir certa gama de diferentes significados. Martin Heidegger lembra-nos que, etimologicamente, método é uma palavra de raiz grega e que significa "o caminho pelo qual sigo uma coisa". No mesmo sentido, Friedrich Rapp afirma que "en su sentido más estricto por 'método' ha de entenderse una manera consecuente de proceder que se aplica para alcanzar un determinado fin"”, Cit. Oliveira, «Método Jurídico e interpretação do direito: Reflexões programáticas sobre a concretização dos direitos coletivos», p. 98. Entre outros vide Quivy E CAMPENHoudT, Manual de investigação em ciências sociais, p. 48; STAKE, The Art of case study research, p. 47; Miles e Huberman, Analyse des Données Qualitatives. Recueil de Nouvelles Méthodes, p. 17.

4 Numa dissertação ou tese o método de investigação científica poderá abarcar substancialmente diferente. Existem, entre outros, o método etnográfico, experimental, pesquisa textual ou de campo, triangulação de vários métodos, etc. Gerring, Case Study Research, Principles and Practices,, p. 1

5 Devem-se evitar assuntos sobre os quais recentemente foram feitos estudos, o que toma difícil uma nova abordagem, Marconi e Lakatos, Fundamentos

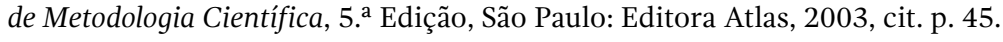

6 Para além das bibliotecas universitárias, as consultas podem ser feitas no repositório científico de acesso aberto de Portugal (https://www.rcaap.pt), no Scielo, Crossref Metadata Search, Google Académico ou na Biblioteca IBCCRIM, entre outros. 
escolhido é discutido na doutrina e, a partir das primeiras leituras, verificar se as posições dos doutrinadores são consentâneas ou, pelo contrário, divergentes. Não existindo celeuma no tema que se tem em vista abordar será de repensar escrever sobre ele. Efetivamente, a produção científica visa acrescentar algo ao que já existe nessa matéria e dar um contributo de evolução na discussão desse tema. Um tema que seja unânime na doutrina acaba por ser um "não tema", tornando-se desinteressante e, acima de tudo, tem fortes probabilidades de nunca ser publicado ${ }^{7}$.

Após as primeiras leituras o autor deverá decidir pela viabilidade da sua investigação, elaborando um projeto de índice e as questões que pretenderá ver respondidas. É importante formular hipóteses, desenvolver as mesmas no corpo do texto que vai elaborar e concluir com as suas soluções para os problemas formulados. Como refere C. Roberto Hernández SAMPIERI et al, as hipóteses indicam-nos o caminho que estamos provando ou tratando provar ${ }^{8}$. Os quesitos ou hipóteses não necessitam de ser verdadeiros, podem ou não ser comprovados com o desenrolar da investigação ${ }^{9}$. O que as distingue é a circunstância de não serem uma afirmação de facto, antes indagações com o fito de se obter uma resposta. O embrião do artigo científico acaba por ganhar a sua forma primária e ao longo do trabalho poderá sofrer alterações, quer por força de novas interrogações, que venham a surgir, quer de outras pesquisas bibliográficas mais centradas no tema em investigação.

William E. MAgnusson ${ }^{10}$ estabelece cinco regras básicas para a escrita de um artigo. Segundo este coordenador de pesquisas em ecologia,

7 VASCONCELlos, «A função do periódico científico e do editor para a produção do conhecimento no Direito e nas ciências criminais»,, disponível online em http://dx.doi.org/10.22197/rbdpp.v3i1.34 [acedido em 25 de junho de 2018].

8 Collado Sampieri e Batista Lucio, Metodología de la investigación, p. 76.

9 "[É] uma dificuldade, ainda sem solução, que é mister determinar com precisão, para intentar, em seguida, seu exame, avaliação crítica e solução", cit. VERA, Metodologia da pesquisa científica. Vide também Miñano LACARos, «Presentación del problema bajo una metodología reflexiva para la investigación científica», pp. 109-112.

10 Magnusson, «How to Write Backwards», Bulletin of the Ecological Society of America, p. 88, disponível em http://www.jstor.org/stable/20168029 [acedido em 23 de julho de 2018]. 
do Instituto Nacional de Pesquisas da Amazónia, o artigo deverá começar pelo fim, escrevendo as conclusões, passando pelos resultados, métodos de investigação e discussão do tema, até finalmente a introdução. $\mathrm{O}$ processo dessas cinco regras permite obter um texto coerente, contendo a informação necessária para apresentar as perguntas e desenvolver as mesmas, para as quais as conclusões a que chegou.

A escolha da forma como se redige um artigo, começando pelo fim, pelo meio ou pelo princípio, deverá partir do seu próprio autor. Não deveremos seguir regras de outros autores só por estes entenderem que o método deles é mais eficiente e profícuo. Cada autor deverá adaptar para si uma forma de escrita, na qual se sinta confortável, desenvolvendo um raciocínio científico que confronte as ideias já existentes e a inovação que lhe pretende dar.

Tratando-se de um artigo deverá limitar-se o número de questões, uma vez que um número elevado poderá levar a que não se aprofunde o cerne da questão e tornem o texto demasiado extenso ${ }^{11}$. Duas a três questões será o ideal, podendo existir subitens nas questões, conforme a complexidade das mesmas, mas não muito extensas.

Quanto às fontes de investigação, deveremos abrir um parêntesis para uma chamada de atenção que se impõe. Com a proliferação da internet torna-se mais fácil efetuar pesquisas recorrendo a motores de busca. Até aqui tudo bem. Efetivamente cada vez mais as bibliotecas e os repositórios das universidades têm o seu acervo documental em páginas da internet. Não se deverá utilizar referências, num artigo científico, quando as mesmas se encontram em páginas que não nos permitem aferir a veracidade do texto ou do seu autor ${ }^{12}$. O recurso a citações muito extensas deverá ser evitado, mas a serem feitas deverão ser efetuadas a partir dos textos originais, levando a uma certeza inequívoca quanto ao

11 Diferentemente numa tese de mestrado ou doutoramento as questões poderão ser em maior número, uma vez que há lugar a uma maior dilação de páginas para abordar as mesmas. Um artigo científico, por regra, deverá ter entre 15 a 25 páginas.

12 Muito menos recorrendo a páginas da Wikipédia. Como nos diz Castro AmoRAS e Vilhena Amoras, «A pesquisa no ensino superior: um ensaio sobre metodologia científica», p. 132, "Por exemplo, há pessoas que afirmam certas informações que não estão adequadamente classificados". 
texto e autoria das mesmas ${ }^{13}$. Na impossibilidade de se consultar a fonte original pode-se recorrer a uma citação já mencionada por outro autor, devendo fazer-se a menção, neste caso, ao autor que efetuou a citação na sua obra. A expressão apud indica que a citação não foi retirada do texto original, mas de um texto de outro autor que citou o original que agora estamos a incluir no nosso artigo. Deverá por isso fazer-se referência tanto ao autor da expressão citada como ao autor de onde se foi retirar a referida expressão ${ }^{14}$.

Desta forma evita-se que existam plágios, facto este que tem vindo a crescer cada vez mais em universidades e que tem levado à anulação de títulos académicos a ilustres conhecidos, como já sucedeu na Alemanha por exemplo ${ }^{15}$.

O artigo deverá ter de forma autonomizada, no mínimo, três partes: introdução, desenvolvimento e conclusão (ou considerações finais). É na introdução que se deverá abordar o tema que se vai desenvolver e colocar as questões que incidem sobre a necessidade de abordar o tema. É também aqui, ainda que de forma sumária, que se poderá incidir sobre o estado da arte no tocante ao assunto em discussão. A introdução é o cotejo do tema e serve para cativar o leitor na continuação da leitura do texto. Deve expor o tema e as questões principais que se vão desenvolver, deixando espaço para que o leitor se possa apaixonar sobre o tema que se

13 As citações com mais de 3 linhas inseridas no corpo do texto, que não constem em nota de rodapé, deverão ser autonomizadas em separado, escritas em itálico e sem necessidade de colocação entre aspas.

14 Exemplo: "[a]ssim, depois de recebido, lido e guardado no computador do destinatário, um e-mail deixa de pertencer à área de tutela das telecomunicações, passando a valer como um normal escrito". RAmos, A prova digital em processo penal: o correio eletrónico, 2. ${ }^{\text {a }}$ Edição, Lisboa: Chiado Editora, 2017, p. 61 apud ANDRADE, "Bruscamente no Verão Passado", Coimbra: Coimbra Editora, 2009.

15 Referimo-nos ao caso do Ministro da Defesa Karl-Theodor zu Guttenberg que lhe foi caçado o título de Doutor por ter plagiado a tese de Doutoramento. Vide http://www.tvi24.iol.pt/internacional/alemanha/ministro-da-defesa-apanhado-a-plagiar-doutoramento [acedido em 2 de agosto de 2018]. Na RBDPP encontra os pressupostos de integridade ética dos autores em http:// www.ibraspp.com.br/revista/index.php/RBDPP/about/editorialPolicies\#custom-2 [acedido em 2 de agosto de 2018]. Em português do Brasil o termo usado para situações como a que referimos é "cassação de título académico". 
vai desenvolvendo e o levem até à leitura das conclusões. Não deverá ser muito extensa, deve, por isso, focalizar-se no tema do artigo e ser direto na abordagem que se vai efetuar.

No desenvolvimento o autor poderá "dar asas" à escrita, tendo sempre como escopo os quesitos que apresentou na introdução. É nesta parte do texto que o autor deverá apresentar as diversas teorias e posições doutrinárias/jurídicas que existem sobre o tema, em ordem às questões que formulou. O seu contributo, quer inovando quer contradizendo ou apoiando determinada posição doutrinária deverá ficar expressa nesta parte do artigo.

Por último a conclusão deverá ser o repisar dos quesitos que pronunciou e as conclusões a que chegou, sendo uma súmula de todo o artigo. Nesta última fase do artigo o autor poderá também aventar novas hipóteses de trabalho a desenvolver no futuro relativamente a situações que não se debruçou, por saírem do âmago do artigo.

Importante na escrita de um artigo científico é o modo de utilização das notas de rodapé. Uma nota de rodapé serve para complementar o corpo do texto ou para fazer referência a um ou vários autores que citamos no texto. Serve essencialmente para que no corpo do texto não exista descontinuidade com o que vem sendo escrito, relevando para o fim de página observações ou explicações que profusamente complementam o texto. Há diversas formas de efetuar referência aos autores que se consultaram para a escrita do artigo. Desde logo o redator do artigo deverá ter em atenção o modo que é utilizado na edição onde pretende publicar o seu artigo e usar a mesma. Tal não só facilita o trabalho dos editores como contribui para uma uniformização da publicação ${ }^{16}$.

O estilo Harvard é o mais utilizado nas ciências sociais correspondendo à referenciação no modelo autor-data (ex. Costa Andrade, 2000, p. 17). Em Portugal a Norma Portuguesa sobre referências bibliográficas (NP 405) utiliza o nome do autor (primeiro o apelido e posteriormente os restantes nomes), título da obra, local de publicação:

16 No que à RBDPP diz respeito poderá encontrar as mesmas em: $<$ https://drive.google.com/file/d/0ByaGv-08dNr5X3JSc1FKektxeVU/view> [acedido em 28 de julho de 2018]. 
Editora, ano de publicação e ISBN ${ }^{17}$. De referir que das páginas web consultadas deverá ser constar o link de acesso, bem como a data em que tal consulta foi efetuada. Tal procedimento permite que se caso a página deixe de estar online se possa recorrer a arquivos da internet para consultar a referida página e constatar o que ali se encontrava publicado nessa data ${ }^{18}$.

Dos vários estilos de efetuar referência aos autores deverá optar-se por um e utilizar o mesmo uniformemente em todo o artigo. Por último referimos ainda que as expressões cuja tradução não seja realizada, tais como locuções latinas ou estrangeirismos, devem ser escritos em itálico.

\section{ReferênCIAs Bibliográficas}

AMORAS, Fernando Castro e AMORAS, Aluana Vilhena, «A pesquisa no ensino superior: um ensaio sobre metodologia científica», Estação científica (UNIFAP), Macapá, v. 6, n. 3, set/dez 2016, DOI: http://dx.doi.org/10.18468/estcien.2016v6n3.p127-136

ASTI VERA, Armando. Metodologia da pesquisa científica. Porto Alegre: Globo, 1976.

ECO, Umberto, Como se faz uma tese em ciências humanas, 13. ${ }^{a}$ Edição, Lisboa: Editorial Presença, 2007.

GERRING, Jonh, Case Study Research, Principles and Practices, New York: Cambridge University Press, 2007.

MAGNUSSON, William E., «How to Write Backwards», Bulletin of the Ecological Society of America, Vol. 77, No. 2 (Apr., 1996), p. 88, disponível em http://www. jstor.org/stable/20168029

${ }_{17}$ A título de exemplo veja-se em https://www.uc.pt/fcdef/documentosbiblioteca/Bibliotecadigital/NP [acedido em 3 de agosto de 2018] ou MeIRIM, Como pesquisar e referir em Direito. O autor ensina-nos diferentes modalidades de referir, desde as monografias, aos sites, à jurisprudência de tribunais, etc, justificando que "o nosso trabalho é potenciador da elaboração de outros textos, sendo por isso importante que a sua divulgação pública obedeça a certas convenções, respeite algumas regras básicas."

Entre outros sugerimos a consulta do site www.archive.org. 
MARCONI, Marina de Andrade e Lakatos, Eva Maria, Fundamentos de Metodologia Científica, 5. ${ }^{\text {a }}$ Edição, São Paulo: Editora Atlas, 2003.

MIÑANO LACAROS, Juan Guillermo «Presentación del problema bajo una metodología reflexiva para la investigación científica», QUIPUKAMAYOC, Revista de la Facultad de Ciencias Contables, Vol. 22 N. 42 pp. 109-112 (2014) UNMSM, Lima - Perú, http://dx.doi.org/10.15381/quipu.v22i42.11043

MEIRIM, José Manuel, Como pesquisar e referir em Direito, Coimbra Editora, 2008. MILES, M. e Huberman, M., Analyse des Données Qualitatives. Recueil de Nouvelles Méthodes, $2^{\mathrm{a}}$ edição. Bruxelles: De Boeck Université, 2003.

OLIVEIRA, Rafael Tomaz de, «Método Jurídico e interpretação do direito: Reflexões programáticas sobre a concretização dos direitos coletivos», Revista Brasileira de Direito, IMED, Vol. 9, n. ${ }^{\circ}$ 2, jul-dez 2013. https://doi.org/10.18256/2238-0604/ revistadedireito.v9n2p90-129

QUIVY, R.; CAMPENHOUDT, L., Manual de investigação em ciências sociais, Lisboa: Grádiva, 1992.

RAMOS, Armando Dias, A prova digital em processo penal: o correio eletrónico, 2. ${ }^{\mathrm{a}}$ Edição, Lisboa: Chiado Editora, 2017.

SAMPIERI, C. Roberto Hernández; Collado, Carlos Fernández e Lucio, Pilar Batista, Metodología de la investigación, México: McGraw-Hill, 1991.

STAKE, R., The Art of case study research, Thousand Oaks, CA: Sage Publications, 1995.

VASCONCELLOS, Vinicius Gomes de. A função do periódico científico e do editor para a produção do conhecimento no Direito e nas ciências criminais. Revista Brasileira de Direito Processual Penal, v. 3, n. ${ }^{0}$ 1, 2017. Disponível online em: http://dx.doi.org/10.22197/rbdpp.v3i1.34 


\section{Informações adicionais e declarações do autor (integridade científica)}

Declaração de conflito de interesses (conflict of interest declaration): o autor confirma que não há conflitos de interesse na realização das pesquisas expostas e na redação deste editorial.

Declaração de autoria (declaration of authorship): todas e somente as pessoas que atendem os requisitos de autoria deste editorial estão listadas como autores.

Declaração de ineditismo e originalidade (declaration of originality): o autor assegura que o texto aqui publicado não foi divulgado anteriormente em outro meio e que futura republicação somente se realizará com a indicação expressa da referência desta publicação original; também atesta que não há plágio de terceiros ou autoplágio.

\section{COMO CITAR ESTE EDITORIAL:}

RAMOS, Armando D. Editorial: Como elaborar um artigo científico para publicação. Revista Brasileira de Direito Processual Penal, Porto Alegre, vol. 4, n. 3, p. 921-930, set./dez. 2018. https://doi.org/10.22197/rbdpp.v4i3.192

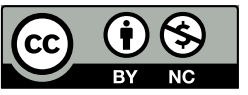

Esta obra está licenciada com uma Licença Creative Commons Atribuição-NãoComercial 4.0 Internacional. 